\title{
A Mobile Anaesthetic - Rapid Evacuation from Hospital
}

\author{
Maj LA KNiemiro* \\ MB, BS, DA(UK), FCAnaes, RAMC
}

33 Field Hospital, BFPO 637

SUMMARY: The use of the Triservice Anaesthetic Apparatus for the emergency evacuation of an anaesthetised patient from nuclear, biological and chemical (NBC) collective protection in a tented hospital complex in the Gulf is described. Because of its compact size and portability the Triservice Anaesthetic Apparatus may prove to be ideal for use in emergency evacuation.

\section{Introduction}

During the Gulf crisis surgical facilities at 33 Field Hospital were contained inside NBC Collective protection (Colpro). This is an interlocking series of Porton liners with a plenum ventilation system which prevents the ingress of chemical agents. The ever present threat of hostilities may necessitate rapid evacuation from this complex.

A case of the rapid evacuation of a patient whilst maintaining safe anaesthesia using the Triservice Anaesthetic Apparatus (TSA) is described.

\section{Case Report}

A 22 year old soldier was scheduled for extraction of his third molars under general anaesthesia. He was premedicated with morphine $15 \mathrm{mg}$ intramuscularly one hour preoperatively. An antisialogue was not prescribed as it was felt to be dangerous to abolish the patient's ability to sweat in the high ambient temperatures. Similarly, an intravenous infusion of Hartmanns solution was established to maintain hydration. The patient was monitored using a Critikon Oxyshuttle pulse oximeter and Critikon Dinamap 8100 vital signs monitor.

After preoxygenation (at 4 litres/min via the Houtonox valve) anaesthesia was induced with propofol $2.5 \mathrm{mg} / \mathrm{kg}$, suxamethonium $1.5 \mathrm{mg} / \mathrm{kg}$ and fentanyl 1 $\mathrm{mcg} / \mathrm{kg}$. A nasal endotracheal tube and throat pack were inserted and vecuronium $0.08 \mathrm{mg} . \mathrm{kg}$ administered. Anaesthesia was maintained using the Triservice apparatus (Fig 1) and the Cape TC50 field ventilator with isoflurane at $1-1.5 \%$ in air supplemented with oxygen at 1 litre/minute.

Shortly after removal of the right lower tooth, a fire adjacent to theatres, caused the alarm to be sounded and the theatres to be plunged into total darkness due to the automatic closedown of the generators. Unfortunately the reserve light source (Darey lamps which run off 12 volt car batteries) was unavailable on this occasion. The immediate solution to this problem was provided by the ever useful laryngoscope followed by torchlight. Immediate evacuation of patient and staff was imperative.

Removing the patient from theatre entailed lifting the stretcher off the MacVicar operating table (Fig 2) and *Now Senior Registrar, Cambridge Military Hospital, Aldershot, Hants GU11 2 AN

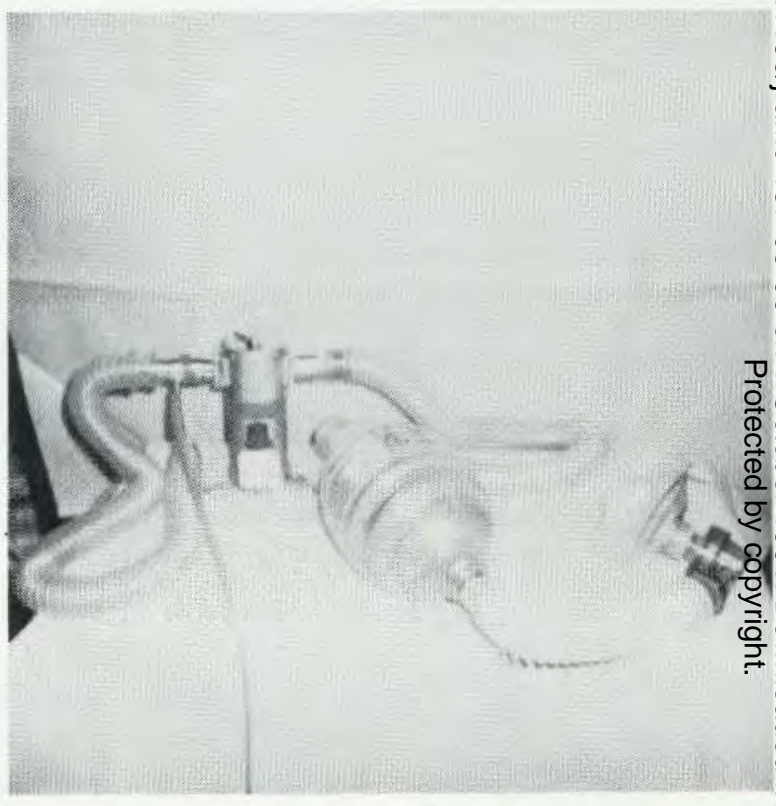

Fig 1. The Triservice Anaesthetic Apparatus consisting of an Oxford Miniature Vapouriser, Sander's T-piece and lightweight tubing.

carrying it around the various obstacles and framework obstructions out of theatre and the hospital complex to safety. Any attempt to wheel a patient trolley along the $\vec{\sigma}$ congested smoke-filled corridor with an anaesthetic machine could have caused a potentially lethal delay.

The TSA was disconnected from the ventilator and $\frac{5}{3}$ placed on the stretcher alongside the patient's head. Ventilation was continued using a self-inflating manual resuscitation bag. Supplemental oxygen was provided by an oxygen cylinder and suction by a portable Ambu foot- $-\frac{}{J}$ operated suction pump. Rapid evacuation out of the $\frac{D}{0}$ complex to safety was achieved in less than two minutes.

Anaesthesia was continued using the TSA until the $\mathbb{N}^{-}$ theatre was pronounced safe enabling the patient to be $N$ transferred back for completion of surgery. Recovery was uneventful with no recall of awareness. 


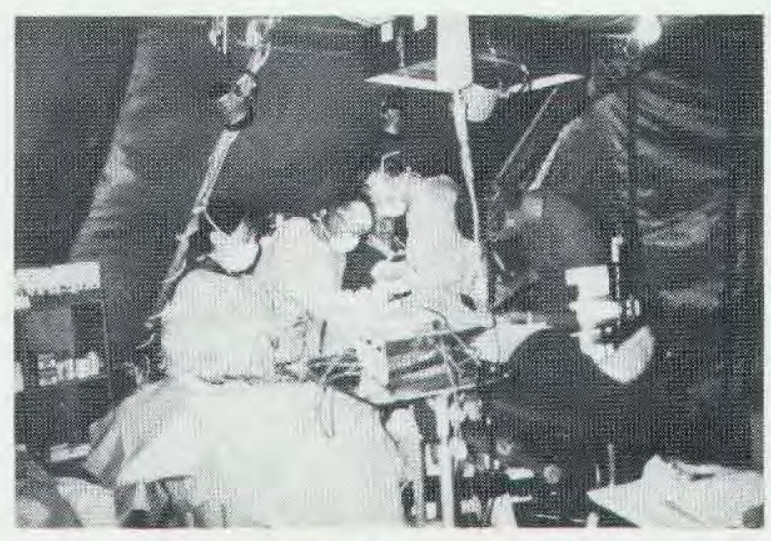

Fig 2. The Oral Surgical team operating on a patient inside COLPRO.

\section{Discussion}

The eight table operating theatre of the Field Hospital was sited within four interlocking Porton liner bubbles within the tented hospital complex. Filtration units supplied a plenum ventilation system preventing the influx of air poisoned with chemical agents. This allowed both patients and staff to operate freely without the encumbrance of chemical protection suits. Each bubble contained two complete operating tables, ancillary equipment and surgical teams. Negotiating each stretcher around the obstacle course of tables and along the interconnecting narrow corridors was both time consuming and cumbersome and any attempt to do this with a Boyle's machine would have been virtually impossible.

The TSA is a light, portable, anaesthetic apparatus which has been used in a variety of situations $(1,2)$. Since the TSA works on the draw-over principle, the majority of patients can be safely ventilated without supplemental oxygen but, additional oxygen should be used as soon as it is available (3).

This case has relevance to peacetime practice should it be necessary to evacuate an anaesthetised patient fro theatre. Inability to use lifts during a fire may necessit escape down flights of stairs and movement of a Boyles machine is impractical. The TSA provided safe maßtenance of anaesthesia during evacuation.

It was felt that it would be valuable to establish? prepacked emergency box for the evacuation of one $\overrightarrow{\overrightarrow{\text { Fr}}}$ more anaesthetised patients from theatre. Our box coftained a complete TSA, endotracheal tub laryngoscopes, a selection of basic anaesthetic drugs $\overline{\bar{n} \text { a }}$ portable Ambu foot-operated suction pump, a few baबic surgical instruments and swabs, in addition to an oxyg్g్ cylinder and Houtonox valve.

With hindsight, monitoring could have accompanied the patient by disconnecting the pulse oximeter and Dinamap from the mains electrical supply.

ल

To summarise, the TSA and an emergency box wस्सुాe extremely useful in enabling the rapid evacuation of the patient from theatre in this case. It is recommended the peacetime anaesthetic departments consider providicowg similar equipment for the safe maintenance of anaesthesia in an emergency.

\section{Acknowledgments}

The author wishes to thank Major R Bailie and L the C A Pailthorpe for their invaluable assistance in क्षి paration of this manuscript, and Col L Kessel L/R P for permission to present this patient.

\section{REFERENCES}

1. Hovghton I T. The Triservice Anaesthetic ratus. Anaesthesia $1981 ; 36$ : 1094-1108.

2. KNIGHT R J, Houghton I T. Field experience the Triservice Anaesthetic Apparatus in Oman a Northern Ireland. Anaesthesia 1981; 36:1122-112 0

3. Tighe SQM, TURner GA, Merrill SE, Pethybridge R J. Minimum oxygen requiremers during anaesthesia with the Triservice Anaestheo Apparatus. A study of drawover anaesthesia in the young adult. Anaesthesia 1991; 46: 52-56. 